friend Mr. Gardner of his first successful vaccination. Pasteur had a sleepless night of anxiety when he had completed his first inoculations for rabies on a human being. Lister, a member of the Society of Friends, could write, "I don't think any case ever excited me so much", in referring to his first use of antiseptic ligatures. Graham Bell and Edison were delighted with the telephone and the phonograph respectively. Lord Kelvin, having devised a delicate electrical instrument, would have it brought to his drawing-room mantelpiece, so that he might exult over it at leisure. So the story continues. The joy of the creative intellect, whether in art, literature or science, is one of the most exalted human emotions.

\section{Drops and Splashes}

Two public lectures under the auspices of the British Association were given at Preston (September 16) and at Rochdale (September 17) by Prof. Allan Ferguson, who took as his subject "Splashes and What They Teach". The lectures dealt with the phenomena attendant on the formation and separation of a drop of water at the end of a vertical tube, the splash of a drop of liquid falling into a liquid, of a solid sphere falling into a liquid and of a drop of mercury falling on to a horizontal sheet of glass. As is well known, experiments were carried out by Worthington some forty years ago in order to elucidate some of these happenings. Photographic technique was then very primitive, and Worthington's experiments were carried out under difficult conditions. Recently a high-speed camera has been developed, in which the film is drawn continuously through the camera at a speed of about thirty miles an hour. A prism rotating rapidly about a horizontal axis is placed between the lens system of the camera and the film, and throws a picture of the object downwards on the film, so that, for a fraction of a second, the image is stationary relative to the film. In this way it becomes possible to take pictures at the rate of 2,000 a second, and therefore, by running them through a projector at the rate of 20 a second, to alter the time-scale in the ratio of a hundred to one. The films so taken corroborate in a remarkable manner the results obtained by Worthington's method of taking separate photographs of drops, each at a different stage of its fall.

\section{Caucasian Studies}

To remedy the neglect of a field in which the Russian literature, with a virtual monopoly created by circumstance, can do less than justice, a society has been founded in England for the promotion of Georgian and Caucasian studies. The promoters include Sir Oliver Wardrop and Mr. W. E. D. Allen, who are among the foremost authorities on Georgia in the West. Sir Denison Ross is the Society's first president. The Society will publish a journal under the title Georgica, of which the first part has already appeared. Its contents, for most of which natives of Georgia, recognized as authorities, are responsible, indicate that breadth of interest, combined with sound scholarship, will be the aim of its promoters. Georgica will also endeavour to keep its readers abreast of current developments in Caucasian studies not otherwise readily accessible. As preliminary matter, Sir Denison Ross contributes an introductory note explaining the objects and methods of the new society, and Mr. W. E. D. Allen reviews the present state of Caucasian studies. Among the remaining papers are a discussion of Georgian chronology by Prof. Taqaishvili, an examination of the Asianic element in Georgian paganism by Prof. M. Tseretelli (seo p. 512 of this issue of Nature), a census of Georgian manuscripts in England, of which there are three important collections, by the Archimandrite Peradze, and an account of the Holy Lance of Echmiadzin by Mr. F. J. Baddeley, who considers that it is identical with the lance discovered in the siege of Antioch in 1098. Dr. A. Gugushvili adds a valuable, if tentative, system of Georgian phonetics, which, it may be hoped, will lead to further discussion. The honorary secretary of the Georgian Society is Dr. A. Gugushvili, to whom inquiries should be addressed at Commonwood House, Chipperfield, Herts.

\section{Exhibition of Photography}

THE eighty-first Annual Exhibition of International Photography by the Royal Photographic Society was opened on September 11. It will remain open daily (Sundays excepted) from 10 a.m. until 9 p.m. (Tuesdays and Fridays excepted-lecture evenings-when it will be closed at 6 p.m.) until Saturday, October 10. Pictorial photography occupies the principal galleries and, as usual, has attracted exhibitors from all over the world. Among the scientific exhibits are two infra-red photographs taken by A. W. Stevens and O. A. Anderson from about 69,780 feet above the ground over Central South Dakota on November 11, 1935. One of these is a vertical photograph, the other lateral. The latter is said to be the first photograph to show the division between the troposphere and the stratosphere. The horizon, 330 miles away from the camera, is clearly arched. The trade sections, though not extensive, are well worth inspection. The emphasis among apparatus is upon the miniature cameras. Instructional exhibits include explanations of the working of the Pola screens and of the Kodachrome process, the effects of varying the filter in making photomicrographs of stained sections and the troubles that may arise through mishandling photographic materials.

\section{Smoke Abatement Exhibition at the Science Museum}

AN exhibition on the abatement of smoke will be opened at the Science Museum, South Kensington, by the Minister of Health, the Right Hon. Sir Kingsley Wood, M.P., on October 1, and will remain open until October 31. It has been arranged by the National Smoke Abatement Society (by permission of the director of the Museum, Colonel E. E. B. Mackintosh), with the co-operation of interested Government departments and industrial associations. Models and other exhibits demonstrating the efficient combustion of coal in steam-raising and other industrial operations will be shown, and other sections 
will be devoted to the uses of other natural fuels, namely, anthracite and anthracitic coals, and oil. Another section will exhibit material relating to the generation, distribution, and uses of electricity. The pre-treatment of coal will be demonstrated by exhibits on high-temperature carbonization (gasworks practice) for the preparation of town's gas and gas coke, and on low-temperature carbonization, in which the product of principal interest is the semicoke. For the scientific investigation of the smoke problem, methods for the measurement of smoke are required, and an exhibit of the Fuel Research Station will be concerned with current researches on this subject, which are being carried out with the view of developing a domestic fire that will burn coal smokelessly. The Department of Scientific and Industrial Research will show exhibits on the nature and causes of smoke, and on the investigation of atmospheric pollution. A section of the exhibition will be devoted to material demonstrating the effects of smoke. The Annual Conference of the National Smoke Abatement Society will be held at the Museum on October 14-17, and will be opened by Captain Harry Crookshank, M.P., Secretary for Mines. Particulars of this Conference may be obtained from the Secretary of the Society, at 36 King Street, Manchester 2.

\section{The World Power Conference}

The third World Power Conference, which was opened at Washington on September 7, was one of the largest technical conferences ever held. The British party, which travelled by the Queen Mary, numbered about a hundred. According to the Electrical Times of September 10, the records of the papers and discussions will run to more than three million words. As there was no hall in Washington large enough for a banquet of 3,000 delegates, the official banquets were held in the waiting hall of the railway station, suitably transformed for the purpose. Each country submitted papers to the Conference setting forth its own particular power problems and questions connected with them. Economic, technical and allied subjects were all discussed. The papers from each country having to be read before a mixed international audience, largely American, were naturally mainly reports of the country from which they originated. The British papers therefore were mainly of interest to all dwelling outside Britain. An exception may perhaps be made for the paper read by S. E. Britton, the city electrical engineer of Chester. His paper was entitled "Rural Electrification in Great Britain". When the use of electricity produces a revenue equal to twenty per cent of the outlay on the electrical distribution system, the inhabitants in rural areas can get a supply of electricity for all purposes at economic rates and use it for the same purposes as those residing in urban areas. Information is given of the annual expenditure on heat, light and power by those living in rural areas who use electricity and those who do not. The paper is clearly written and is very complete. It is particularly applicable to the conditions prevailing in the neighbourhood of Chester.

\section{German Chemical Engineering}

ALтночgн a certain amount of publicity was obtained in the scientific journals, trade papers and the daily Press for the German Chemical Engineering Exhibition held at Cologne in 1934, the organizers felt that these reports were necessarily incomplete, and so they have published the Achema Jahrbuch, 1935-36 (Berlin : Verlag Chemie, G.m.b.H.), to give some indication of the recent progress in chemical engineering illustrated by that exhibition, which was visited by 48,600 representatives of industrial firms and professional men from forty-six countries. Opportunity is also taken of directing attention to Achema VIII, which will be held on July 2-11, 1937, at Frankfort-on-Main, where accommodation amounting to 240,000 square feet of floor space will be available for exhibitors. In this exhibition, one building will be reserved for firms wishing to show scientific instruments and equipment such as are used industrially for making technical measurements or controlling and regulating the flow of fluids, heat and electricity. Another building will house industrial apparatus made of non-metallic materials, whilst the third and fourth buildings are reserved for machines used in the artificial silk and associated industries, and largesize equipment for the chemical and allied industries respectively. It is intended to publish at the beginning of 1937 a catalogue giving detailed information of the exhibition. The "Jahrbuch" also gives a list of the exhibitors at the 1934 exhibition in English, French and German as well as notes in two of these languages on some of the more important sections and the equipment which was shown.

\section{Magnetic Observations in New Zealand and elsewhere}

OwING to the world economic crisis and ather causes, many magnetic and meteorological observa. tories, including those of some great nations, have fallen seriously into arrears with their publications. The ideal, approached, if not always attained, by the chief British observatories, is to publish the observations of one calendar year before the end of the next. Now that the great and successful co-operative effort of the Second International Polar Year has been accomplished-so far as the observations go, though the publication and, still more, the discussion of the results is still very incomplete-a desirable goal for new effort on the part of geophysical observatories would be to overtake their arrears of publication within an assigned time, say by the end of 1940. A step in this direction has been taken by New Zealand in publishing three years records of the Christchurch Magnetic Observatory in one volume (Annual Re. ports for 1931, 1932, 1933. Wellington : Government Printing Office, 1936. Pp. 132. 10s. 6d.). The volume naturally consists almost entirely of tabular matter, and for economy is reproduced directly from type. script, in a reasonably satisfactory manner. The magnetic data refer (as for 1930) to the Amberley sub-station, about twenty-five miles from Christchurch. Monthly mean daily variations are given for all days (with Fourier analysis) and international quiet days, but (regrettably) not for international 